\title{
The Effects of Film Appreciation on Improving the Students' Intercultural Communication Competence
}

\author{
Jiao Xue \\ English Department, Zhenjiang Watercraft College, Zhenjiang, China \\ Email: shadowvi@163.com \\ Qi Pan \\ English Department, Zhenjiang Watercraft College, Zhenjiang, China
}

\begin{abstract}
With the global economic integration and the increasing exchanges between the outside world and China, effective communication becomes an important topic in intercultural communication. Foreign language education is not merely the teaching of language, and it should cultivate students' intercultural communication competence in different cultural backgrounds, which becomes the new objective of current foreign language education. Film is the microcosm of a nation's cultural life, so it is an important way to learn a nation's cultural background. Therefore, film appreciation lesson is an important way for culture teaching and at the same time shows the authentic English, which makes it superior in cultivating students' intercultural communication competence.
\end{abstract}

Index Terms - intercultural communication competence, language teaching, culture teaching, film, film appreciation lesson

\section{INTRODUCTION}

Globalization creates a world in which people of different cultural backgrounds have more chances to communicate with each other. As English is now the world's most widespread language existing and functioning as a world language, the intellects who can conduct intercultural communication with fluent English are badly in need. However, under the current educational system, most students cannot reach the average communication level after their six years' learning of English. The first reason is the currently prevailing grammar-translation pedagogy. The second reason is lacking intercultural communication awareness. They regard passing various kinds of tests as their only goal. However, the final goal of English teaching should be cultivating intercultural communication competence of students. As Brooks proposes, in today's world, to learn a language only for its linguistic sake is not enough nor is it completely possible, for language in nature is a means of communication (Brooks,1997). So how to improve students' intercultural communication competence becomes very important.

Through the unique form of dynamic pictures, films can show a lot of things vividly to the audiences, and it can effectively give the students intercultural experience without the costs of time to visit the countries and cultures. Applying films in classroom teaching can gradually make them understand target language and the culture of that country and at the same time improve their overall comprehension of English, so as to improve their intercultural communication competence finally. This paper aims to explore the effects of English film appreciation on improving the intercultural communication competence of the English language learners in China.

\section{INTERCULTURAL COMMUNICATION COMPETENCE}

\section{A. The Definition of Intercultural Communication Competence}

Intercultural communication competence has been conceptualized in various ways. It varies according to the researcher's theoretical orientation or specific sample being studied. In the past twenty years, there has been a growing consensus on the conceptualization. As a reflection of this consensus and purpose of this essay, we choose the definition which is proposed by William B. Gudykunst (2007): "intercultural communication competence involves the knowledge, motivation and skills to interact effectively and appropriately with members of different cultures"(p.192). According to him, there are four implications entailed in this conceptualization. They are different cultures, effectively and appropriately, to interact, knowledge, motivation and skills. Competent intercultural communication requires all these three components. These three components can be learned through education, experience and guided practice. So this gives hints to teachers about the specific ways to develop students' intercultural communication competence. They can refer to them as guidelines and objectives when designing a lesson.

It is worth mentioning that the culture here not only include the target culture and learners' native culture, which we 
have mentioned in the previous chapter, but also other cultures, because intercultural communication competence is a flexible communication competence which takes the learning, exchanging, reflecting and experiencing between the target language, target culture and learners' native language and native culture as the channel and at the same time takes into account the characteristics of other cultures. It is ability for people from different cultures around the world to conduct effective communication. If foreign language teaching rules out other cultures, it is bound to cause learners to linger between target culture and learners' native culture and ignore the existence of other cultures, which is not good for the cultivation of intercultural communication competence. Although because of time and energy constraints, itis impossible for the learners to learn and experience various cultural systems at the same time, to some extent, learning some characteristics of other cultures is feasible. It can be done through the choosing of teaching materials and designing of teaching methods.

Of course, it is not an easy job to combine language and culture in foreign language teaching. Expansion of teaching content and unfamiliarization with teaching objectives will make it hard for less-experienced teachers. So, it is necessary for the teachers to have discussions before class to find an appropriate way and design it meticulously.

\section{B. The Cultivation of Intercultural Communication Competence}

The ultimate goal of English teaching is to cultivate intellects with intercultural communication competence. However, for a long time, the scholars, whether in traditional linguistics, structural linguistics, or transformational generative linguistics, all think that language itself is the research object in language study. Thus, traditional foreign language teaching falls into a mistake to cultivate students' pure language competence. Though the students can make grammatically-correct sentences and bear the ability for reading comprehension, they can't conduct effective communication. Communication competence is reflected not only in the correctness of grammar but also in the social appropriateness of speech act, so the improvement of communication competence requires the students to understand the culture system which language reflects, and adjust their cognitive schemata and reference frame through the comparison of target culture and their own culture. Only concerning about language symbols and language form is clearly meaningless. Therefore, to improve intercultural communication competence, the best way is to combine culture teaching and language teaching together.

\section{Film Appreciation as a TeAChing Tool to Improve Students' Intercultural CommunicATiOn Competence}

\section{A. The Characteristics of Film}

Film is probably the most challenging cultural product for language teaching. It is designed to appeal most directly and fully to students' emotions. The unique characteristics of film create an experience that often goes beyond what we can experience in reality, and it also adds to communication power. Champoux (1999) summarizes the characteristics of film which give it unbeatable power as a teaching tool.

1. Close-up shots: shows a viewer something that might go unnoticed with ordinary vision.

2. Long shots: let a viewer see an image unavailable to ordinary humane vision.

3. Focusing techniques: show a physical reality as seen by humane eye or show it in a different way. It can be divided into deep focus and soft focus.

Deep focus: refers to having all parts of a scene in focus from the nearest object to the farthest. This focusing method duplicates the way a humane would see a scene.

Soft focus: keeps the objects nearest the viewer in focus and puts objects farther away out of focus. This method emphasizes one part of a scene and de-emphasizes another. A director can control the emotional delivery of a scene to get a viewer response.

4. Film editing: puts a series of images together in a unique sequence intended to have specific effects on the viewer. The resulting stream of images creates a viewer experience that transcends simply recording physical reality.

5. Sound: sound includes dialogue and music.

Dialogue: the delivery of dialogue adds to the drama, humor, or satire of a scene.

Music: music can be divided into composed music and music taken from other sources.

Composed music: gives desired effects to the cinematic experience through deliberate control in tempo, loudness, and color. These effects include emotion, emphasis of specific scenes, anticipation of coming events, and hints of an off-screen character.

Music taken from other sources: often has meaning for viewer from earlier exposure to the music; lets a director use borrowed music as a satirical device or emphasize meaning to certain film theme.

6. Special effects: a film making tool that brings enhancement.

These unique characteristics contribute to the power of the film, though we seldom realize that because we often watch a film just for entertainment. The teachers can take advantage of these characteristics to let the students better understand a film when using film as a teaching tool in class.

\section{B. The Advantages of Using Film Appreciation as a Teaching Tool to Improve Students' Intercultural Communication Competence}

Film appreciation is an important means to help improve students' comprehensive ability of vision, hearing, speaking 
and writing. It can stimulate students' interest in learning, achieve context-orient teaching and incorporate language learning and culture learning. It provides a possibility for the students to conduct study to their own interest and characteristics.

Jane Sherman(2003) summarize 6 advantages of using authentic video in language teaching with explanations for each, which is also fit for film appreciation lesson for film is no doubt one kind of authentic video.

For its own sake: people want access to English language world.

For comprehension of the spoken language: video brings us all kinds of voices in all kinds of situations, with full contextual back-up.

As a language model: authentic video provides a vast up-to-date linguistic resource of accents, vocabulary, grammar and syntax, and all kinds of discourse, which shows us language in most of its uses and contexts-something neither course book nor classroom can do.

For culture: video is a window on English-language culture.

As a stimulus or input: video can be used for discussions, for writing assignments, as input for projects or the study of other subjects.

As a moving picture book: video gives access to things, places, people, events and behavior, regardless of the language used, and is worth thousands of picture dictionaries and magazines.

We can see that it is difficult to fulfill this range of functions except by living in an English-speaking country- an opportunity that most learners do not have. Film helps to substitute for this experience; it brings the English-language world to the learners. Jane Sherman's summary also lets us better understand why film appreciation is a good tool to improve intercultural communication competence. As mentioned in the previous chapter, the best way to cultivate intercultural communication competence is to incorporate language teaching and culture teaching. Film is this kind of authentic video that can combine these two aspects.

\section{Possible Problems}

For teachers

On mindset. Due to the characteristics of the profession as a teacher, experience plays an important role in teaching; however, it is experience that often hinders the application of new teaching ideas and education techniques. Because some teachers have engaged in teaching for many years and they are used to traditional teaching methods, they may feel hard to handle the application of multimedia in class. And some teachers may have resistance for they think there is no need to spend a lot of money and energy to learn the same knowledge that traditional teaching method can offer. This will affect their enthusiasm of using multimedia, thereby affecting the range of the application of it, as a result, the advantages of using multimedia in teaching cannot be truly reflected.

On media manipulation. The multimedia class is characterized by various kinds of multimedia, which requires a reasonable and timely combination by the teachers. Some teachers may have no idea about what to do when facing these multimedia, and therefore they cannot use them effectively, which will fail to optimize the effect of multimedia.

On teaching forms and teaching methods. Due to the traditional teaching forms and teaching methods, some teachers regard film appreciation lesson as an adjunct to traditional teaching, and they do not deep study the teaching methods of film appreciation lesson, not to mention to appropriately select multimedia and accurately implement, thus impossible to jump out of the routine of the traditional teaching methods.

For the students

On learning attitude. Students are the core of the classroom, and film appreciation will finally be applied to the students, thus the attitude of the students on film appreciation lesson will directly affect the outcome. The attitudes of the students can be generally divided into two kinds. The first is that the students are interested in film appreciation and benefit from it, thus they will accept it consciously. The second is that the students are interested in the equipment and think it's very fun, but this curiosity will disappear overtime, thus affecting teaching effects.

\section{EARLY-STAGE PREPARATIONS}

As there are many problems existing in the implementation of film appreciation lesson, the teachers must make good preparations before class.

\section{A. Clarification of Teaching Purpose}

China's rapid economic development requires more and more talents who can communicate well in English; as a result, the ultimate goal of English teaching turns into cultivating intellects with intercultural communication ability. Film appreciation lesson, as a language practice course, aims at raising students' listening and speaking level and cultivating their communication ability in English through providing a more authentic language environment and language training opportunities. However, in order to adapt to social development, to meet the needs of the times, film appreciation lesson should also develop students' reading and writing skills as well. So the specific teaching purposes of film appreciation lesson are summarized as follows:

1. To enable students to learn some language skills, some slang and some oral expressions, which will benefit their spoken English. 
2. To enhance students' listening ability through some listening practices of the film.

3. To develop students' reading and writing ability through after-class reading and writing as well as some exercises.

4. To enable students to realize cultural differences between target culture and their own culture, and by discovering the target culture's differences, deepening the understanding of their own culture, thus grasping characteristics of each culture. During the discovering process of differences, common ground mustn't be neglected.

5. To develop students' intercultural awareness and communication ability dealing with cultural differences by watching and discussing the films and some flexible classroom activities, like role-play and content repeating etc.

\section{B. Analysis of Teaching Objects}

Through six years of English learning in middle and senior school, university students have already had some basic knowledge of English language, which set up the basic premise of film appreciation lesson. But as the students are still in the development stage, their characters are neither stable nor mature, they are less able to focus and have low capacity to judge what is right and what is wrong, they are easy to feel tired and distracted after long-time listening training. It is psychological characteristics, personality characteristics and language skills that determine the teaching methods and choice of the film.

\section{Selection of Films}

There is no doubt that film is not perfect and not all the films are fit for classroom. The teachers should take in consideration of many aspects, like the content of the film, difficulty level etc. Because watching a film that students don't understand or they are not interested in is a very negative experience. So the teachers should know what factors will hinder comprehension and try to minimize them by choosing an appropriate film.

Jane Sherman (2003) summarizes some factors which hinder comprehension of a film:

High verbal density, i.e. a lot of speech with very little action, Words which don't match the action, e.g. in smart dinner-table conservation; words which are in conflict with the action or are an ironic commentary on it.

A high degree of naturalism in the speech, e.g. everyone talking at once, mumbled asides, actors with their backs to the camera, in consequential dialogue.

Cartoons-mouths, faces and body language are not as expressive as those of real people.

Dialect and regional accents-local color in the film generally means local confusion in the viewer.

Period language, e.g. Shakespeare remains difficult in spite of some wonderful adaptations; however, in film adaptations of classic novels, clear drama-school enunciation often triumphs over archaic language.

So when choosing a film, teachers should avoid the film that have these disadvantages. In the author's opinion, selecting a film should adhere to the following principles:

1. Pertinence

Select different film according to different teaching objectives. There are various kinds of English films, but not all the films are suitable for English learning and the improving of intercultural communication competence. Teachers should select the film according to the students' English level. In most English films, the characters are changeful, and people's voice tone, speed and sound quality are quite different, which are difficult to understand. So the films the teachers choose should be relatively simple in language and relatively slow in speech rate. Moreover, as mentioned in the previous chapter, culture teaching in an important way to improve intercultural communication competence, so the film chosen should bear abundant cultural characteristics. Of course, a film can only reflect some aspects of a certain culture, and few films are particularly made to reflect a specific culture. It is very hard or almost impossible for the teachers to find a film that has all useful segments reflecting culture. The teachers should choose the film which highlights the culture that meets pedagogical needs.

2. Ideological content

Young college students are plastic, and their thoughts are unstable which are receptive to new ideas. Therefore, the material selected should be healthy, praise the good and the beautiful, and praise justice, peace and progress. Evoke emotion and sympathy of the students through life-like images so that they can consciously accept aesthetic edification, ideological and moral education.

3. Scientificity

In terms of the access to information and the characteristics of teaching progress, teachers should pay particular attention to the language, the amount of information and length of the film. In the film selected, the language should reach basic standards, speech rate moderate and linguistic information abundant, linguistic signals clear and have less dialect and slang. Meanwhile, it is better to do without Chinese subtitles, or the students can understand the film through the screen actions and subtitles, which will fail to train the students' language skills. If the voice signal is weak and background noisy, students will have difficulty in acquiring information and it is hard for film appreciation lesson to achieve good teaching effect. If there are too much dialect and slang which the students don't understand in the film, they will fail to obtain language knowledge. So the film selected must be rich in linguistic information, clear in voice signal and appropriate for learners.

Besides, after each class, teachers should inquire students about the film so that they can get the feedback in time. They can ask the students whether they understand the film, whether they are interested in it and whether they learn something etc. Therefore, they can learn from it and make better choice next time. 


\section{CONCLUSION}

Though the teaching and learning effects of film appreciation lesson have not been fully tried and tested in the classroom yet, the author explains how film appreciation lesson improves learners' intercultural communication competence theoretically. Film appreciation lesson has rich theoretical basis and obvious superiority, but it cannot reach the intended purpose if there is no scientific design and careful implementation. So the teachers should make a good preparations before class.

The author thinks that the value and potential of film appreciation lesson should be fully exploited for foreign language study. Though it is a challenging job for both teachers and students, the author believes it will have a prosperous future if more efforts are made.

\section{REFERENCES}

[1] Brooks, N.(1997). Teaching Culture in the Foreign Language Classroom, in P.R. Heusinrveld (ed.), Pathways to Culture: Readings on Teaching Culture in the Foreign Language Class. NY: Intercultural Press.

[2] William B. Gudykunst. (2007).Cross-cultural and Intercultural Communication. SH: Shanghai Foreign Language Education Press.

[3] Joseph E. Champoux. (1999). Film as a Teaching Source. Journal of management inquiry, 8, 240-251.

[4] Sherman, J. (2003). Using Authentic Video in the Language Classroom. UK: Cambridge University Press.

[5] Grant, B. K. (1983). Film Study in the Undergraduate Curriculum. NY: The Modern Language Association of America

[6] Dodd, C. H. (1998). Dynamics of Intercultural Communication. Boston: Mc Graw-Hall.

Jiao Xue was born in Yangzhou, china in 1986. She received her M.A degree in foreign linguistics and applied linguistics from Jiangsu University of Science and Technology, China in 2011.

She is currently a tutor in English Department, Zhenjiang Watercraft College, Zhenjiang, China. Her research interests include Second Language Acquisition and intercultural communication.

Qi Pan was born in Zhenjiang, China in 1987. She received her B.A. degree in English language and literature from Jiangsu University of Science and Technology, China in 2009.

She is currently a tutor in English Department, Zhenjiang Watercraft College, Zhenjiang, China. Her research interests include Second Language Acquisition Contrastive Studies of English and Chinese. 